\title{
IRON DEFICIENCY AS A RISK FACTOR FOR FIRST FEBRILE SEIZURE
}

Rahul Majumdhar' ${ }^{1}$ Haricharan. K. R. ${ }^{2}$, Venkatamurthy.M³.

1. Resident, Department of Pediatrics, Adichunchanagiri Institute of Medical Sciences, BG Nagar, Mandya.

2. Assistant Professor, Department of Pediatrics, Adichunchanagiri Institute of Medical Sciences, BG Nagar, Mandya.

3. Professor, Department of Pediatrics, Adichunchanagiri Institute of Medical Sciences, BG Nagar, Mandya.

\section{CORRESPONDING AUTHOR:}

Dr. Haricharan. K. R.,

Prakash Sadana, Ist Cross, B.G. Layout, Mandya, Karnataka- 57140.

E-mail: dr.haricharan@gmail.com

ABSTRACT: OBJECTIVES: Estimation of Iron status in children with first febrile seizure (FFS). Iron status was evaluated by including Hemoglobin, Mean Corpuscular Volume (MCV), Mean Corpuscular Haemoglobin (MCH), Serum ferritin. MATERIALS AND METHODS: Study was conducted all children with first febrile seizures and febrile illnesses (FI) in Pediatrics Intensive Care Unit and Pediatrics Wards of Sri Adichunchanagiri Institute of Medical Sciences, B.G. Nagara from January 2010 to June 2011. The blood samples from the 50 children comprising the cases and 50 children comprising the controls constituted the material for the study. RESULTS: In the present study 58\% cases were diagnosed as Iron Deficiency Anemia (IDA) with Febrile Seizure (FS); 18\% controls were diagnosed as IDA with Febrile Illness. IDA was more frequent among children with FS than those with febrile illness alone. The result suggests that IDA may be a risk factor for FFS. Screening for IDA should be considered in children with FFS.

CONCLUSION: Iron Deficiency Anemia is associated with the severity of a febrile illness, and more severe cases could be more likely to get seizures.

KEY WORDS: Iron Deficiency Anemia, First Febrile seizure

INTRODUCTION: Febrile seizures are a form of acute symptomatic seizures occurring in $2 \%$ to $5 \%$ of children and are the most common form of childhood seizures and believed to have unfavourable prognosis 1,2 and to cause brain damage and subsequent epilepsy ${ }^{3,4}$.

Over the past 25 years, much more information on FS has accumulated from both human and animal studies ${ }^{5}$. The prognosis for febrile seizures usually has been found to be good. Such seizures are not associated with any detectable brain damage ${ }^{6,7,8}$, and epilepsy will eventually develop in only a small minority of children who have had FS7,8,9,10.

Febrile seizures is defined by International League Against Epilepsy (ILAE) as a seizure occurring in association with a febrile illness in the absence of a CNS infection or acute electrolyte imbalance in children older than 1 month age without prior afebrile seizures ${ }^{11}$.The febrile illness must include a body temperature of greater than $38.4{ }^{\circ} \mathrm{C}$, although the increased temperature may not occur until after the seizure. The child may be neurologically normal or abnormal.

No specific upper age limit is used. Febrile seizures are most common between the ages of 6 months and 3 years, with peak incidence at 18 months of age. Onset after 7 years age is uncommon. 
Febrile seizures are classified as simple if it is an isolated, brief, generalized seizure; or complex if it is focal, prolonged (lasting for more than 10 minutes 9,12 , or 15 minutes ${ }^{12,10}$ or multiple (occurrence of more than one seizure during the febrile illness).

MATERIALS AND METHODS: The study was a prospective study conducted on all children with first febrile seizures and febrile illnesses in Pediatrics Intensive Care Unit and Pediatrics Wards of Sri Adichunchanagiri Institute of Medical Sciences, B.G. Nagara from January 2010 to June 2011. Cases and Controls comprised of children with FS and children with febrile illness, respectively. The blood samples from the 50 children comprising the cases and 50 children comprising the controls constituted the material for the study.

\section{METHOD OF COLLECTION OF DATA:}

The case group included 50 children fulfilling the following criteria:

- INCLUSION CRITERIA (Aged between 6 months to 6 years, First febrile seizures occurring in association with a febrile illness in the absence of CNS infection or any other defined cause of seizures)

- EXCLUSION CRITERIA (Children with previous febrile seizures, Neurological infections, Developmental delay, Children on Iron therapy).

The control group included 50 children aged 6 months to 6 years who got admitted with febrile illness without febrile seizures.

All children included in the study had the following done:

1) Demographic data, seizure details, nature of febrile illness, family history of epilepsy/ febrile seizures, temperature and nutrition status, protein energy malnutrition as per the IAP classification.

2) Estimation of haemoglobin, red blood cell indices and plasma ferritin.

3) Iron deficiency anaemia will be defined as haemoglobin $<11 \mathrm{~g} / \mathrm{dl}$, MCV $<70 \mathrm{fl}$, MCH $<27 \mathrm{pg}$ and plasma ferritin $<12 \mu \mathrm{gm} / \mathrm{dl}$.

RESULTS AND OBSERVATIONS: This is a prospective study conducted over a period of 18 months from January 2010 to June 2011 conducted in the department of Pediatrics, Sri Adichunchanagiri Institute of Medical Sciences and Research Centre, B.G.Nagara.

In the study the mean age of onset of FS is 24 months, with early onset between 6 months to 1 year was found in $36 \%$ of cases

The mean weight of cases was $9.88 \pm 2.35 \mathrm{~kg}$ and in control group was $8.24 \pm 1.29 \mathrm{~kg}$.

There is excess of male children in FS group (62\%) without statistical significance 100\% cases were of lower SES, $96 \%$ controls were of lower SES, $4 \%$ of controls were of middle SES.

Among $78 \%$ cases seizures lasted for $<5$ mins, in 22\% cases seizures lasted for 5-10 mins, among $4 \%$ controls seizure lasted for more than 10 mins. $8 \%$ cases and $2 \%$ controls had positive family history of febrile seizures which did not reach statistical significance.

Overwhelming 98\% cases had generalized tonic-clonic seizures and focal seizures were reported in only $2 \%$ of cases. 


\section{ORIGINAL ARTICLE}

Table-1

\begin{tabular}{|l|l|l|l|}
\hline $\begin{array}{l}\text { Temperature } \\
\text { at admission } \\
\left({ }^{0} \mathrm{~F}\right)\end{array}$ & $\begin{array}{l}\text { Cases } \\
(\mathrm{n}=50)\end{array}$ & $\begin{array}{l}\text { Controls } \\
(\mathrm{n}=50)\end{array}$ & P value \\
\hline $100-101$ & $15(30.0 \%)$ & $4(8.0 \%)$ & $0.005^{* *}$ \\
\hline $101-102$ & $14(28.0 \%)$ & $17(34.0 \%)$ & 0.517 \\
\hline $102-103$ & $18(36.0 \%)$ & $24(48.0 \%)$ & 0.224 \\
\hline $103-104$ & $3(6.0 \%)$ & $5(10.0 \%)$ & 0.461 \\
\hline
\end{tabular}

In the study, except for initial rise in temperature (Table-1) of the body at around $100-101{ }^{0} \mathrm{~F}$ temperature, we couldn't find any significance in peak temperature at admission between FS and FI groups 74\% cases and 40\% controls had no Protein Energy Malnutrition (PEM); 18\% cases and 12\% controls Grade I PEM; 10\% cases and 28\% controls had Grade II PEM; 4\% controls had Grade III PEM; no cases and controls had Grade IV PEM.

All the cases presented within 24 hours from onset of seizures and single seizure in a febrile episode was reported.

The range of triggering illnesses were similar in cases and controls and URTI predominated in both the groups

Children with febrile seizure were more Iron deficient in terms of low HB, low MCH, low MCV, low plasma ferritin, low serum Iron, high TIBC (Table-2) and low serum transferrin as compared to control group.

The mean value for $\mathrm{Hb}$ in cases was $8.92 \pm 1.18$ and in controls was $9.55 \pm 0.96$.

The mean value for MCV in cases was $67.03 \pm 15.63$ and in controls was $84.12 \pm 13.78$.

The mean value for MCH in cases was $30.60 \pm 13.81$ and in controls was $37.32 \pm 9.57$.

Mean plasma ferritin level was $45 \pm 64.09(45 \%)$ in cases and $54.22 \pm 24.02(55 \%)$ in control.

Mean serum iron level was $77.65 \pm 44.71(45 \%)$ in cases and $95.20 \pm 38.08(55 \%)$ in controls.

Mean TIBC level was 434.86 \pm 125.18 (55\%) in cases and 354.14 \pm 103.10 (45\%) in controls.

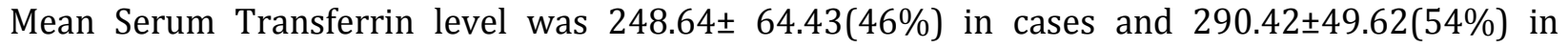
controls.

\section{Graph 1-Case-Disease diagnosis}

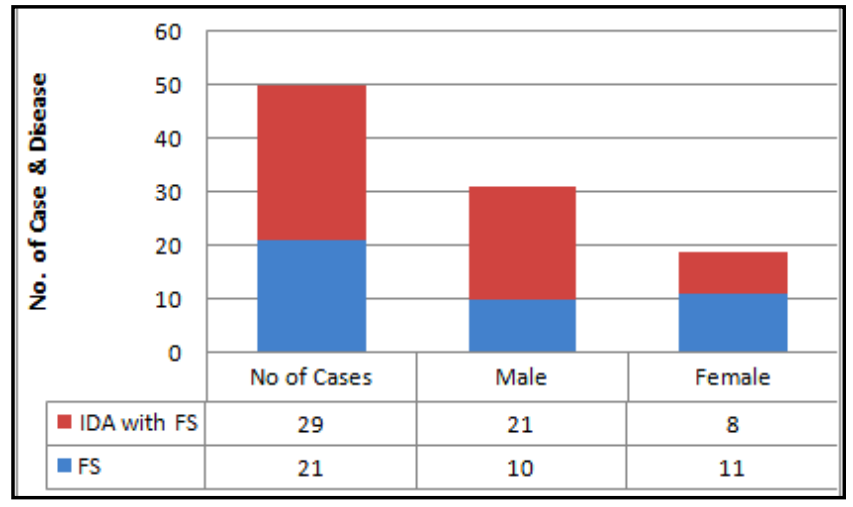


58\% cases (Graph-1) were diagnosed as IDA with Febrile Seizure; 18\% controls were diagnosed as IDA with Febrile Illness; 21\% cases of FS were present in the current study.

DISCUSSION: The mean age of onset in present study is 24 months which is comparable to the other studies. Separate studies done by Vaswani RK et $\mathrm{al}^{\mathbf{1 3}}$ and Waruiru C et al ${ }^{14}$ also found that FS peaks at 18 months. Ellenberg et al ${ }^{6}$ found the average convulsion age to be 23.3 months. It is generally noted that the febrile convulsion and the first febrile convulsion are more common in second year. Besides mean age of FS, many large scale studies have demonstrated young age as a risk factor for complex febrile convulsion e.g. Wallace et al ${ }^{15}$, Al-Eissa et al ${ }^{16}$, Farwell et al ${ }^{17}$ and Berg et al ${ }^{18}$.

In present study the mean weight is significantly less in controls as compared to cases whereas Vaswani et al $^{13}$ didn't find any significant difference of weight in case and control group of their study.

There was a preponderance of male in present study for the febrile seizure group. Regardless of the era of the study or particulars of the design; boys have consistently emerged with higher frequency of febrile seizures. Incidence ratios of boys: girls have ranged from 1.1:1 to 2:1 (Nelson and Ellenberg; Hauser; Forsgren et al 10,19,20). Whether there is a biological basis for the gender-specific differences in febrile seizure susceptibility, or whether boys just contract more fevers and therefore are at greater risk, is currently not established.

Shorter the duration of recognized fever, higher the chances of recurrence. For those with FS within an hour of onset, the recurrence risk at $1 \mathrm{yr}$ was $46 \%$, compared with $39 \%$ for those with prior fever lasting 1 to $24 \mathrm{hrs}$ and 15\% for those with more than $24 \mathrm{hrs}$ of recognized fever before the FS. Berg et al ${ }^{18}$ found $44 \%$ infants had experienced less than $1 \mathrm{hr}$ of fever at the time of their FS, only $13 \%$ had fever more than 24 hrs duration. In present study, all the cases presented within 24 hrs from onset of fever which was almost similar to the above quoted studies.

Study conducted by Eden AN et al 21 in an urban setting with an equal mix of lower and middle SES groups, noted that $10 \%$ of $1-3$ yr old had IDA ${ }^{21}$. In present study, being a rural hospital, all the cases and controls were from lower SES.

There is relative preponderance of single seizure in a febrile episode in present study which comparable to the western figures put forward by Farwell et al17. Occurrence of febrile status and focal seizures were absent in present study similarly reported by Shinnar et al $^{18}$.

In present study we have used a cut off definition of $\geq 15$ minutes for febrile status, which is an older definition. We think the cut off limit of 15 minutes is plausible, as because simple FS is, by definition lasts up to 10 or 15 minutes.

In present study, simple febrile seizures constituted $96 \%$ of the seizures while $4 \%$ were focal seizures; similar to study by Livingston et $a l^{2}$, where majority (96.9\%) was simple FS.

In present study family history is slightly more in cases as compared to controls, though, more males than females had a significant family history of FS similar to studies done by Khalid $\mathrm{N}$ et $a l^{23}$.

In present study, except for initial rise in temperature of the body at around $100-101{ }^{\circ} \mathrm{F}$, we couldn't find any significance in peak temperature at admission between FS and FI groups.

Upper respiratory tract infection is the commonest trigger of febrile seizure in present group of children and no statistical difference could be made out with the control group, as per different etiology. This is in keeping with Nelson and Ellenberg (1978) and Millichap et al(2006). 
Analysis for Iron deficiency as a risk factor for febrile convulsion was done in the present study, by biochemical and hematological investigations. Diagnostic threshold employed in present study for Iron deficiency were $\mathrm{Hb}$ level $<11 \mathrm{~g} / \mathrm{dl}$, MCV $<70 \mathrm{fl}, \mathrm{MCH}<27 \mathrm{pg}$, Plasma Ferritin $<12$ $\mu \mathrm{g} / \mathrm{dl}$, Serum Iron $<60 \mu \mathrm{g} / \mathrm{dl}$, TIBC $>450 \mu \mathrm{g} / \mathrm{dl}$, Transferrin $<250 \mathrm{mg} / \mathrm{dl}$.

Iron has been found to act as a cofactor in a number of enzymatic reactions at the cellular level and effects neurotransmitter production and function, hormone function, and DNA replication. Deficiency of iron, therefore, results in disruption of normal cell and organ function.

Iron deficiency is associated with neurological problems in young children, including developmental delay, stroke, breath-holding spells and pseudotumor cerebri.

In present study mean $\mathrm{Hb}, \mathrm{MCV}$ and $\mathrm{MCH}$ was $8.92 \mathrm{~g} \%, 67.03 \mathrm{fl}, 30.66$ pg respectively which was significantly low in cases and compared to control. Kumari PL et $a l^{24}$ and Naveed-ur-Rehmann et al $^{25}$ had results similar to our study.(Table-3)

In present study, there was variation of the iron level with FS and FI group.

Table-2 Comparison of serum Iron, TIBC Level between cases and controls

\begin{tabular}{|l|l|l|l|}
\hline \multirow{2}{*}{$\boldsymbol{\mu g} / \mathbf{d L})$} & \multirow{2}{*}{ Mean } & \multirow{2}{*}{ SD } & Level of significance \\
\cline { 4 - 4 } & & & $\mathbf{p}$-value \\
\hline Iron & & & \\
\hline FS cases & 77.65 & 44.7 & 0.037 \\
\hline FI-Control & 95.2 & 38.08 & \\
\hline TIBC & & & \\
\hline FS cases & 434.86 & 125.18 & 0.001 \\
\hline FI-control & 354.14 & 103.1 & \\
\hline
\end{tabular}

Table-3-Comparison of various blood parameters in different studies

\begin{tabular}{|l|l|l|l|l|l|l|l|l|}
\hline Study & $\begin{array}{l}\text { Age } \\
(\mathrm{mths})\end{array}$ & $\begin{array}{l}\mathrm{Hb} \\
(\mathrm{gm} \%)\end{array}$ & $\begin{array}{l}\mathrm{MCV} \\
(\mathrm{fl})\end{array}$ & $\begin{array}{l}\mathrm{MCH} \\
(\mathrm{pg})\end{array}$ & $\begin{array}{l}\mathrm{PF} \\
(\mu \mathrm{g} / \mathrm{dl})\end{array}$ & $\begin{array}{l}\text { S.Fe } \\
(\mu \mathrm{g} / \mathrm{dl})\end{array}$ & $\begin{array}{l}\text { TIBC } \\
(\mu \mathrm{g} / \mathrm{dl})\end{array}$ & $\begin{array}{l}\text { S Transf. } \\
(\mathrm{mg} / \mathrm{dl})\end{array}$ \\
\hline Kobrinsky et al & $6-36$ & $<11$ & $<72$ & $<24$ & $<20$ & - & - & - \\
\hline$\underline{\text { Pisacane } \text { et al }}$ & $6-24$ & 10.5 & $<70$ & & $<5$ & - & - & - \\
\hline$\underline{\text { Daoud } \text { et al }}$ & $3-72$ & $<11$ & $<72$ & $<24$ & $<30$ & - & - & - \\
\hline $\begin{array}{l}\text { Naveed-ur } \\
\text { Billoo } \text { et al }\end{array}$ & $8-36$ & $<10$ & $<70$ & $<24$ & $<10$ & - & - & - \\
\hline Vasvani et al & $8-27$ & 9.4 & 73.4 & 21.4 & 31.9 & - & - & - \\
\hline Khalid N et al & $13-18$ & $8.2-9.6$ & $\begin{array}{l}55- \\
63\end{array}$ & $8-14$ & - & - & $\begin{array}{l}438- \\
575\end{array}$ & - \\
\hline Present study & $9-39$ & 8.92 & 67.03 & 30.6 & 45 & 77.65 & 434.86 & 248.64 \\
\hline
\end{tabular}

CONCLUSION: The association between iron deficiency anemia and febrile seizures has been studied before without any conclusive reports and this study was done for further confirmation. None the less, selection bias as well as confounding by social class does not seem likely in this study. 
IDA was more frequent among children with FS than those with febrile illness alone. The result suggests that IDA may be a risk factor for FFS. Screening for IDA should be considered in children with FFS. Fever can worsen the negative effect of anemia or for iron deficiency on the brain and a seizure can occur as a consequence. Alternatively, anemia can be associated with the severity of a febrile illness, and more severe cases could be more likely to get seizures.

All the investigations carried out to evaluate iron deficiency anemia were significantly lower in cases as compared to controls. This suggests that iron deficient children are more prone for febrile seizures.

A follow up study of patients found to be iron deficient at the time of first febrile seizure to determine the incidence of subsequent febrile seizures after treatment for iron deficiency would be of great interest.

\section{REFERENCES:}

1. Lennox WG. Significance of febrile convulsions. Pediatrics 1953;11:341

2. Livingstone S, Bridge EM, Kajdi L. Febrile convulsions: A clinical study with special reference to heredity and prognosis. J Pediatr 1947; 31:509.

3. Fowler M. Brain damage after febrile convulsions. Arch Dis Child 1957; 32:67.

4. Wallace RH, Berkovic SF, Howell RA, et al. Suggestion of a major gene for familial febrile convulsions mapping to 8q13-21. J Med Genet 1996; 33:308.

5. Baram TZ, Shinnar S, eds. febrile seizures. San Diego: Academic Press, 2002.

6. Ellenberg JH, Nelson KB. Febrile seizures and later intellectual performance. Arch Neurol 1978; 35:17.

7. Verity CM, Golding J. Risk of epilepsy after febrile convulsions: A national cohort study.BMJ 1991; 303:1373.

8. Verity CM, Ross EM, Golding J. Outcome of childhood status epilepticus and lengthy febrile convulsions: Findings of National cohort study. British Med J , 1993;307;225.

9. Annegers JF, Hauser WA, Elveback LR, et al. The risk of epilepsy following febrile convulsions. Neurology 1979; 29:297.

10. Nelson KB, Ellenberg JH. Predictors of epilepsy in children who have experienced febrile seizures. N Engl J Med 1976; 295:1029.

11. Commission on Epidemiology and Prognosis, international league against epilepsy. Guidelines for epidemiologic studies on epilepsy.Epilepsia1993;34:592

12. Berg AT, Shinnar S. Complex febrile seizures. Epilepsia 1996a; 37:126

13. Vaswani RK; Dharaskar PG ; Kulkarni S; et al. Iron deficiency as a risk factor for first febrile seizure. Indian Pediatr. 2010; 47(5):437-9.

14. Waruiru C, Appleton R. Febrile Seizure: An update. Arch Dis Child 2004; 751-6.

15. Wallace SJ. They don't do very well. Pediatrics 1975; 678.

16. alEissa YA, alOmair AO, alHarbish AS et al. Antecedents and outcome of simple and complex febrile convulsions among Saudi children. Dev Med Child Neurol 1992; 34:1085-90.

17. Farwell JR, Blackner G, Sulzbacker S, et al. First febrile seizures. Characteristic of the child, the seizures, and the illness. Clin Paediatr Phila 1994; 33:263-7.

18. Berg AT, Shinnar S. Complex febrile seizures. Epilepsia 1996; 37:126-33. 


\section{ORIGINAL ARTICLE}

19. Hauser WA. The prevalence and incidence of convulsive disorders in children. Epilepsia 35, (Suppl. 2), S1-6.

20. Forsgren L, Sidenvall R, Blomquist et al. An incidence case reference study of febrile convulsions in children: Genetics and social aspects. Neuropediatrics 21,153-159.

21. Eden AN, Mir MA. Iron Deficiency in 1-3 year-old children. A pediatric failure? Arch Pediatr Adolesc Med 1997; 151(10):986-8.

22. P Leela Kumari, MKC Nair, SM Nair, et al. Iron Deficiency as a Risk Factor for Simple Febrile Seizures- A Case Control Study Indian Pediatrics 2011 May 30.

23. Khalid N, Akrem M, The association between Iron Deficiency Anemia and First Febrile Convulsions. Duhok Med J 2010; 4(1):60-66.

24. P Leela Kumari, MKC Nair, SM Nair, et al. Iron Deficiency as a Risk Factor for Simple Febrile Seizures- A Case Control Study Indian Pediatrics 2011 May 30.

25. Naveed-ur-Rehman, Billoo AG. Association between iron deficiency anemia and febrile seizures. J Coll Physicians Surg Pak. 2005 Jun; 15(6):338-40. 